Трубкина А. И.

\begin{abstract}
Аннотация. Цель исследования состоит в выявлении взаимной детерминированности имплицитности и коммуникативно-прагматических функций художественных деталей. В статье рассматриваются имплицированные смыслы, актуализированные художественной деталью, в аспекте прагматических функций художественного текста. Научная новизна заключается в том, что художественные детали в рассказе А. П. Чехова «Дама с собачкой» описаны на основании существующих классификаций с привлечением функционального критерия, что позволяет изучать художественный текст в координатах его воздействия на адресата. В результате анализа текста определено, что в нем представлены художественные детали различных типов, при этом их коммуникативно-прагматические функции, обусловленные имплицированными смыслами художественного текста, обнаруживают определенный синкретизм и лабильность дифференцирования.
\end{abstract}

\title{
Literary Detail: Implicitness and Communicative-Pragmatic Functions
}

\author{
Trubkina A. I.
}

Abstract. The research aims to identify the mutual determinacy of implicitness and the communicativepragmatic functions of literary details. The paper considers implicit meanings actualised by a literary detail from the perspective of the pragmatic functions of a literary text. Scientific novelty lies in the fact that the literary details in A. P. Chekhov's short story “The Lady with the Dog” are described on the basis of existing classifications involving a functional criterion, which allows the researcher to study the literary text in terms of its impact on the addressee. As a result of analysing the text, it has been found that it contains literary details of various types, with their communicative-pragmatic functions, which are dependent on implicit meanings of the literary text, revealing a certain syncretism and differentiation lability.

\section{Введение}

Совершившийся в середине XX в. поворот в лингвистике был ознаменован обретением человеком статуса организующего центра смыслового пространства, что обусловливает особое внимание к тем лингвистическим феноменам, которые связывают высказывание с его продуцентом. Само обращение к автору высказывания как к объекту исследования акцентировало внимание на актуальных сферах развития науки о языке и обеспечило динамичное формирование методологии прагматики: в этой связи закономерным стал переход от анализа статичной и фиксированной семантики слова к изучению динамики смысла высказывания [6; 13]. 3начения лексем и лексических сочетаний оказались тесно связанными с реальностью их употребления в речевой цепи, что позволило трактовать значение высказывания как неразрывно связанное с прагматической ситуацией, с коммуникативными целями речевого акта: «Прагматика представляет собой именно тот участок лингвистической теории, который широко, настойчиво и последовательно эксплицирует коммуникативную сторону языкового функционирования и употребления. Это человеческий фактор в языке» [9, с. 19].

Художественная деталь представляет собой важный компонент смыслового пространства художественного текста, благодаря которому автор кодирует информацию, имплицируя ее. Под художественной деталью понимают «мельчайшую изобразительную или выразительную художественную подробность; элемент пейзажа или портрета, отдельную вещь, поступок, психологическое движение» [17, с. 75]. Особое значение приобретают при этом те невербализованные смыслы, которые актуализирует автор в художественных деталях, а также проблематика их декодирования читателем.

Актуальность исследования состоит в необходимости выявления коммуникативно-прагматической специфики художественного текста, которая закономерно вызвана исследовательским интересом не только

Научная статья (original research article) | https://doi.org/10.30853/phil210449

(c) 2021 Авторы. ООО Издательство «Грамота» (๔ 2021 The Authors. GRAMOTA Publishers). Открытый доступ предоставляется на условиях лицензии СС BY 4.0 (open access article under the CC BY 4.0 license): https://creativecommons.org/licenses/by/4.0/ 
к механизмам транслирования содержащейся в таком тексте информации, но и к тем способам, которые позволяют особым образом воздействовать на читателя. Для отечественной науки о языке приоритетной стала лингвистика текста, включающая и прагматический аспект текста художественного, в рамках которого рассматривается в ряду прочих и проблема воздействия на адресата [7].

Язык рассматривается прагматикой в коммуникативном аспекте, т.е. в связи с продуцентом и реципиентом высказывания, целями и условиями коммуникативной ситуации, поэтому прагматику трактуют как такое направление в изучении языка, которое дает возможность изучать языковые единицы в их отношении к процессу создания и передачи адресантом (продуцентом), а также понимания реципиентом. Прагматика напрямую соотносится с полезностью, ценностью, понятностью языкового знака, что обеспечивает устойчивый исследовательский интерес к той информации, которая не только извлекается адресатом из текста или высказывания, но определенным образом понимается и оценивается им [11, с. 124-125; 24, с. 389-390; 30].

В этой связи необходимо подчеркнуть значимость проблематики изучения художественной детали с позиций лингвистики, поскольку эта единица смыслового пространства художественного текста как один из эффективных способов воздействия на адресата пока не изучена в достаточной степени. Из последних работ назовем лишь кандидатские диссертации по лингвистическим специальностям И. А. Жаворонок [18], О. И. Просянниковой [35] и Е. Д. Шмидт [42], а также единичные языковедческие статьи [3; 39] в то время как активное изучение художественной детали проводится пока только в рамках литературоведения $[2 ; 12 ; 28 ; 29 ; 36]$.

Задачи исследования:

- рассмотреть существующие в современной филологии точки зрения на художественную деталь как необходимый компонент смыслового пространства художественного текста;

- обосновать значимость имплицированных смыслов в прагматике художественной детали;

- выявить и описать коммуникативно-прагматические функции художественных деталей на основании выявляемых имплицированных смыслов рассказа А. П. Чехова «Дама с собачкой» (1899).

Методы исследования составляют единый комплекс, в котором приоритетными стали дедуктивноиндуктивный метод, примененный в процессе анализа и обобщения различных концепций художественной детали, метод наблюдения и моделирования, позволяющий охарактеризовать лингвистические средства формирования коммуникативно-прагматического потенциала художественной детали, метод лингвистической интерпретации, направленный на декодирование имплицированных смыслов, детерминированных художественными деталями.

Теоретическую основу исследования составили постулаты теории текста, изложенные в работах Р. Барта [6], И. Р. Гальперина [10], Т. М. Николаевой [33], концепции художественного текста, предлагаемые Н. С. Болотновой [7], М. Я. Дымарским [16], А. В. Кузнецовой [21; 22], Д. С. Лихачевым [25], Ю. М. Лотманом [26], а также теории имплицитности И. В. Арнольд [4], А. В. Бондарко [8], М. В. Никитиным [32], В. Н. Телия [38]. Особое место в формировании теоретико-методологической базы исследования занимают работы в сфере прагмалингвистики и теории коммуникации О. В. Александровой [1], Г. Баранова [5], Т. А. ван Дейка [13], Г. Г. Матвеевой [30], Е. В. Падучевой [34].

Практическая значимость исследования состоит в возможности использования его результатов при проведении лекционных и семинарских занятий по курсам «Современный русский язык», «Филологический анализ текста», спецсеминаров по теории текста и дискурса, стилистике и лингвокультурологии в вузе.

\section{Основная часть}

Художественный текст направлен на структурирование художественного мира, центром которого выступает человек, его мировосприятие, и эта цель обусловливает формирование тех образных средств, которые становятся востребованными в поэтике того или иного художника слова. Художественный образ обретает целостность посредством включения в художественный мир таких компонентов, как поступки, действия, события, речевые характеристики персонажей, а также пейзажи, интерьеры, портреты и мн. др. Все они образуют сложную систему художественных деталей. Благодаря включению в текст художественных деталей создается хронотоп в сложнейшем взаимодействии пространства и времени действия, описываются портреты персонажей, уточняются фрагменты предметного мира, в котором они действуют. Таким образом, художественные детали позволяют читателю определить проблематику и идею художественного текста на основании результатов декодирования его имплицированных смыслов.

Деталь в художественном тексте является компонентом предметной изобразительности, это сумма малых единиц предметного мира произведения [37], характеризующих идиостиль писателя. А. Б. Есин предлагает классификацию деталей, в которую включены внешние и психологические детали. Среда обитания, внешность и предметное бытие людей могут быть охарактеризованы посредством внешних деталей (портретные, пейзажные и вещные), внутренний мир человека - с помощью психологических деталей. Такая дифференциация условна, т.к. внешняя деталь может стать психологической, включаясь в вербализацию мыслительной деятельности или эмоциональных состояний героя [17].

В. А. Кухаренко предлагает на основании функционального критерия типологию деталей, которая включает изобразительную, уточняющую, характерологическую и имплицирующую детали [23]. На наш взгляд, функции художественной детали зачастую синкретичны, реализуются в художественном тексте в тесном 
единстве друг с другом, однако целесообразно рассматривать коммуникативно-прагматические функции данного компонента смыслового пространства текста, опираясь в лингвистическом анализе и на выделяемый тип художественной детали.

Художественная деталь рассматривается современной филологией как важная часть структуры художественного произведения, это часть художественного целого, раскрывающего внутренний мир человека и окружающую его действительность. Тем не менее, изучение детали и ее коммуникативно-прагматического потенциала может сообщить научному исследованию корректное направление только в случае, если художественные детали будут рассматриваться во взаимодействии с другими компонентами смыслового пространства текста, что в конечном счете создаст необходимый контекст для суждений о структурносемантической организации конкретного художественного текста.

Коммуникативно-прагматический анализ художественного текста приобретает особый эвристический потенциал в случае обращения исследователя к интерпретации невербализованных смыслов, содержащихся в таком тексте. Художественный текст - многоуровневый феномен, имеющий сложную структуру: он включает авторские представления о действительности, организованные особым образом с помощью средств художественной выразительности. Воздействие на адресата осуществляется лингвистическими средствами, которые репрезентируют эксплицитные и имплицированные смыслы в художественном тексте [8], причем именно имплицитные способы становятся определяющим в организации эстетической информации и создают возможность множественности интерпретаций текста.

Через восприятие художественного текста реципиент получает новое знание о мире, пропущенное сквозь призму отношения автора к изображаемому и организованное особым образом с помощью таких языковых средств, которые соответствуют авторскому замыслу: «Хдджжественный текст устроен таким образом, что наряду со сведениями, которые в нем сообщаются в явной форме, он содержит и такую информацию, которую читатель должен “извлечь”, пройдя через цепочку умозаключений. Иначе говоря, текст содержит сведения и идеи, выраженные неэксплицитно, и эта неэксплицитность может составить художественный прием» [33, с. 232].

Линейность традиционно признается одним из определяющих свойств языкового знака, в то время как сознание человека функционирует нелинейно. Так, Е. В. Милосердова указывает, что «уже в рамках традиционной лингвистики высказывались идеи о том, что не все подразумеваемое вводится в предложение и что переход от нелинейной структуры к ее линейному представлению всегда сопровождается тем, что эксплицитно выражается лишь некоторая часть когнитивной структуры, а другие ее части могут присутствовать в имплицитном виде» [31, с. 728]. Лингвистика приходит к закономерному выводу о том, что неоднородность плана содержания высказывания может использоваться в коммуникативно-прагматических целях, когда продуцент намеренно не включает в высказывание его основной смысл, акцентируя внимание реципиента исключительно на побочной информации. Поэтому имплицитность может быть как непроизвольной, так и намеренной (т.е. подтекстовой) [31]. В любой трактовке имплицитности определяющее место принадлежит разграничению значения и смысла [Там же]. Так, В. А. Звегинцев дифференцирует язык в его состоянии и язык в его деятельности, что позволяет утверждать взаимную обусловленность смыслов и значений: «В деятельности общения смысловое содержание всегда представляет собой результат творческого мыслительного усилия, т. к. формируется в неповторяющихся ситуациях, воплощая в себе соотнесение данной ситуации с внутренней моделью мира, хранящейся в сознании человека» [19, с. 97].

Имплицитные высказывания представляют собой не прямую коммуникацию, для которой релевантно наличие скрытых смыслов, не содержащихся в собственно высказывании. Такая не прямая коммуникация направлена на активизацию интерпретативных усилий адресата [36]. В этой связи необходимо особо подчеркнуть, что в норме взаимодействие людей подразумевает общение на уровне выводимого смысла, т.к. мир продуцента и мир реципиента не тождественны. В. З. Демьянков правомерно утверждает, что понимание отличается от простого восприятия знаков именно отсутствием этого тождества [14, с. 62], и такое отсутствие тождества манифестировано даже в процессе интерпретации адресантом собственных высказываний.

Для изучения художественного текста в коммуникативно-прагматическом аспекте определяющим является тезис о диалогичности эстетической коммуникации: художественный текст всегда направлен на диалог, на стимулирование лингвокогнитивной деятельности адресата и декодирование имплицированных смыслов, которые сосредоточены в художественных деталях.

Художественные детали вербализуют в тексте фрагменты индивидуально-авторской и языковой картин мира, которые имплицитно содержат ассоциативные, концептуальные и семантические поля. Поэтому сам творческий процесс можно считать авторской импликацией языковой картины мира на основании кодирования ее фрагментов в смысловом пространстве художественного текста, тогда как рецептивно-интерпретативная деятельность читателя - это развертывание этих имплицированных смыслов, в том числе и через истолкование художественных деталей, системных в соответствии с авторским замыслом.

Рецептивно-интерпретативная деятельность в отношении художественного текста может быть признана корректной только в случае учета взаимозависимости коммуникантов в системе «автор - текст - читатель». При том, что центральная роль автора современной лингвистикой признается аксиоматичной, успешное взаимодействие продуцента художественного текста и его реципиента включает также понимание и восприятие текста в соответствии с авторским замыслом.

А. П. Чехов является признанным мастером художественной детали, и сама авторская манера развития повествования через манифестирование не целого художественного образа, а лишь его части свидетельствует, 
с одной стороны, о повышенном внимании писателя к индивидуализированным проявлениям тех или иных аспектов внешнего мира, с другой - объективирует один из значимых признаков авторского идиостиля, что диалектически связано с самим жанром рассказа, избираемым Чеховым для выражения эстетической идеи. Оставляя в стороне рассуждения о стилистической природе чеховской детали, обратимся к выяснению тех ее прагматических свойств, которые позволяют автору осуществлять многоуровневую коммуникацию с читателем, расширяя границы интерпретации художественного текста.

Так, в рассказе «Дама с собачкой» художественные детали обладают обширным коммуникативнопрагматическим потенциалом, т.к. именно они, в соответствии с авторским замыслом, репрезентируют имплицированные смыслы, которые должны быть адекватно интерпретированы адресатом. Например, в контексте: «Сидя в павильоне у Верне, он <Гуров> видел, как по набережной прошла молодая дама, невысокого роста блондинка, в берете: за нею бежал белый шпиц» [40], - представлен не целостный и подробный портрет героини, а лишь значимые детали, позволяющие читателю задействовать свой житейский и духовный опыт, расширив ассоциативные связи для создания ее художественного образа. Репрезентантами художественных деталей являются в данном случае как существительные (блондинка, в берете, шпиц), так и прилагательные, которые, однако, не трансформируются в чеховском тексте в эпитете (невысокого, молодая, белый). Тем не менее сама лаконичность контекста и скупость описания персонажа свидетельствуют, прежде всего, о поверхностном пока интересе Гурова к «новому лицу» на Ялтинском бульваре, и ничего более, а сама деталь является изобразительной, реализуя выделяющую функцию.

Художественная деталь является важным средством создания художественного образа в случае, если она повторяется в различных контекстах, и именно такой деталью становится берет Анны Сергеевны: «И вот однажды под вечер он обедал в саду, а дама в берете подходила не спеша, чтобы занять соседний стол. Ее выражение, походка, платье, прическа говорили ему, что она из порядочного общества, замужем, в Ялте в первый раз и одна, что ей скучно здесь...» [Там же]. Основной функцией деталей в приведенном контексте становится выделяющая, которая позволяет считать такие детали характерологическими. Гуров ввиду своей опытности видит многое в заинтересовавшей его даме, что не эксплицировано в ее целостном облике (она из порядочного общества, замужем, в Ялте в первый раз и одна, что ей скучно здесь). Иными словами, можно наглядно проследить трансформацию функций деталей и их синтез, целью которых становится воздействие на читателя и стимулирование его рецептивно-интерпретативной деятельности для декодирования имплицированных смыслов.

Интересно, что портретная изобразительная деталь у А. П. Чехова практически никогда не реализует лишь выделяющую функцию: такая деталь в анализируемом чеховском рассказе имеет своей целью не только и не столько обозначить внешние отличительные признаки, но, прежде всего, манифестировать особенности внутреннего мира героя, его восприятие, и через них оказать воздействие на адресата художественного текста. Например, в следующем контексте: ВВспомнил он ее тонкую, слабую шею, красивые, серые глаза» [Там же]. Детализация портрета не направлена на целостное создание образа в сознании читателя, это имплицирующие детали, реализующие психологическую функцию. Лексические сочетания тонкую, слабую шею, красивые, серые глаза позволяют декодировать имплицированный в данном контексте смысл: герой припоминает облик женщины, которая притягивает его.

А. П. Чехов прибегает в своем рассказе и к таким художественным деталям, которые направлены на формирование впечатления читателя о самом герое (а не только о его восприятии героини): «Гурову было уже скучно слушать, его раздражал наивный тон, это покаяние, такое неожиданное и неуместное; если бы не слезы на глазах, то можно было бы подумать, что она шутит или играет роль» [Там же]. В приведенном контексте приоритетны употребления прилагательных (наивный, неожиданное, неуместное), которые сообщают художественным деталям психологическую функцию, эти имплицирующие детали репрезентируют оценку героем состояния героини: Гуров испытывает не просто скуку, он раздражен (можно было бы подумать, что она шутит или играет роль). Таким образом, читатель получает дополнительную имплицированную информацию о характере Гурова, которую необходимо адекватно декодировать в данном контексте.

Значимы в рассказе «Дама с собачкой» и изобразительные детали, приобретающие символическую функцию, например: «Анна Сергеевна смотрела в лорнетку на пароход и на пассажиров, как бы отыскивая знакомых, и когда обращалась к Гурову, то глаза у нее блестели. Она много говорила, и вопросы у нее были отрывисты, и она сама тотчас же забывала, о чем спрашивала; потом потеряла в толпе лорнетку» [Там же]. Такой вещной изобразительной деталью становится в данном контексте лорнетка, являющаяся не необходимой вещью (как бы отыскивая знакомых), а знаком страха Анны Сергеевны перед тем, что неотвратимо должно произойти между ней и Гуровым (вопросы у нее были отрывисты, и она сама тотчас же забывала, о чем спрашивала). То, что она теряет в толпе лорнетку, несет в себе имплицированный смысл: любовь ослепляет ее, и последние попытки бежать от нее давно тщетны.

Подчеркнем также, что в частях рассказа, повествующих о пребывании Гурова в Ялте, количество вещных изобразительных деталей невелико: автор акцентирует внимание читателя в том числе и посредством имплицированных в немногочисленных деталях разного типа смыслов, на внутренних переживаниях, на эмоциях и оценках героя (ср., например: «Совершенная праздность, эти поцелуи среди белого дня, с оглядкой и страхом, как бы кто не увидел, жара, запах моря и постоянное мелькание перед глазами праздных, нарядных, сытых людей точно переродили его» [Там же]). Однако возвращение Гурова в Москву ознаменовано не только отказом, как впоследствии оказалось, лишь временным от общения и встреч с Анной Сергеевной. Описание включает большое количество уточняющих деталей, что, разумеется, оказывает воздействие на читателя, а декодируемый смысл в этой связи должен быть интерпретирован как символический поворот 
от эмоционального в сторону материального, например: «Гуров был москвич, вернулся он в Москву в хороший, морозный день, и когда надел шубу и теплые перчатки и прошелся по Петровке, и когда в субботу вечером услышал звон колоколов, то недавняя поездка и места, в которых он был, утеряли для него всё очарование. Мало-помалу он окунулся в московскую жизнь, уже с жадностью прочитывал по три газеты в день и говорил, что не читает московских газет из принципа. Его уже тянуло в рестораны, клубы, на званые обеды, юбилеи, и уже ему было лестно, что у него бывают известные адвокаты и артисты и что в докторском клубе он играет в карты с профессором. Уже он мог съесть целую порцию селянки на сковородке...» [Там же]. В приведенном контексте представлен целый ряд таких уточняющих деталей, которые организуют мир героя (шубу, перчатки, звон колоколов, газеты, рестораны, клубы, карты, порцию селянки на сковородке). Безусловно, контекстом, в котором также при помощи детализации обозначено предстоящее возвращение Гурова к привычной жизни с супругой в Москве, является следующий: «И, оставшись один на платформе и глядя в темную даль, Гуров слушал крик кузнечиков и гудение телеграфных проволок с таким чувством, как будто только что проснулся» [Там же]. Примечательно, что здесь также репрезентированы изобразительные детали, связанные со слуховыми ощущениями (крик кузнечиков, гудение телеграфных проволок), что несомненно, свидетельствует об изменениях во внутреннем мире героя и его отношении к окружающей действительности в реализации психологической функции художественных деталей.

Проведенный анализ художественного текста рассказа А. П. Чехова «Дама с собачкой» позволяет утверждать, что художественная деталь всегда осознанно употреблена автором в конкретном контексте, направлена на реализацию определенных импликатур, которые, в свою очередь, должны быть корректно декодированы читателем. Художественная деталь у Чехова реализует зачастую символическую функцию, что в данном рассказе, несомненно, связано с самой онтологической темой любви. Так, например, в следующем контексте: «Пройдет какой-нибудь месяц, и Анна Сергеевна, казалось ему, покроется в памяти туманом и только изредка будет сниться с трогательной улыбкой, как снились другие. Но прошло больше месяца, наступила глубокая зима, а в памяти всё было ясно, точно расстался он с Анной Сергеевной только вчера. И воспоминания разгорались всё сильнее. Доносились ли в вечерней тишине в его кабинет голоса детей, приготовлявших уроки, слышал ли он романс или орган в ресторане, или завывала в камине метель, как вдруг воскресало в памяти всё: и то, что было на молу, и раннее утро с туманом на горах, и пароход из Феодосии, и поцелуи. Он долго ходил по комнате и вспоминал, и улыбался, и потом воспоминания переходили в мечты, и прошедшее в воображении мешалось с тем, что будет. Анна Сергеевна не снилась ему, а шла за ним всюду, как тень, и следила за ним. Закрывши глаза, он видел ее, как живую, и она казалась красивее, моложе, нежнее, чем была; и сам он казался себе лучше, чем был тогда, в Ялте. Она по вечерам глядела на него из книжного шкапа, из камина, из угла, он слышал ее дыхание, ласковый шорох ее одежды. На улице он провожал взглядом женщин, искал, нет ли похожей на нее... [Там же], - примечательно то, что герой, окруженный привычными вещами, поглощенный раз и навсегда утвердившимся бытом, рутиной, чувствует даже при созерцании давно знакомых интерьеров постоянное присутствие любимой, и художественные детали только усиливают воздействие имплицированных смыслов на читателя.

Художественная деталь, наряду с другими компонентами структуры художественного текста, направляет восприятие эстетической информации адресатом, обусловливая характер когнитивной деятельности, стимулируемой автором. Поливариативность интерпретаций имплицированных смыслов художественной детализации обеспечивает активное воздействие на индивидуальную картину мира читателя, включая эмоциональную и ценностную сферы личности.

\section{Заключение}

Проведенное исследование позволило прийти к следующим выводам.

На наш взгляд, предлагаемые литературоведами классификации деталей, включающие, с одной стороны, внешние и психологические детали, с другой - изобразительные, уточняющие, характерологические и имплицирующие детали, в процессе анализа художественного текста можно объединить вполне обоснованно, что позволяет также выявить и основные коммуникативно-прагматические функции художественных деталей выделяющую, психологическую и символическую. Эти функции могут быть в известной степени синкретичны.

Художественный текст стимулирует эстетическую когницию адресата, направленную на декодирование имплицированных смыслов, сосредоточенных в художественных деталях. Вербализация в тексте фрагментов индивидуально-авторской и языковой картин мира происходит, в том числе, и благодаря художественным деталям, и эти компоненты имплицируют ассоциативные, концептуальные и семантические поля. Процесс создания художественного текста представляет собой авторскую импликацию языковой картины мира, кодирующую ее фрагменты в смысловом пространстве художественного текста, тогда как рецептивноинтерпретативная деятельность читателя раскрывает эти имплицированные смыслы в том числе и через истолкование художественных деталей, составляющих систему в соответствии с авторским замыслом.

В рассказе А. П. Чехова «Дама с собачкой» представлены детали всех выделяемых типов, при этом их отнесение к тому или иному типу варьирует в зависимости от контекста и имплицированных смыслов, которые заложены в тексте автором. Декодирование имплицированных смыслов и их интерпретация обнаруживают лабильность границ между разными типами художественной детали и синкретизм их коммуникативнопрагматических функций. 
Перспективы исследования заключаются в выявлении коммуникативно-прагматических параметров различных типов художественной детали в корреляции с теми функциями, которые детали реализуют в художественных текстах. Также определенным эвристическим потенциалом обладает изучение художественных текстов с позиций жанровых признаков, которые закономерно оказывают влияние на рецепцию и интерпретацию текстов адресатом.

\section{Источники | References}

1. Александрова О. В. Единство прагматики и лингвопоэтики в изучении текста художественной литературы // Проблемы семантики и прагматики: сб. науч. тр. / Калин. ун-т. Калининград, 1996. С. 3-7.

2. Алексеева Л. В. Художественная деталь в поэтике повести П. И. Мельникова-Печерского «Гриша» // Проблемы исторической поэтики. 2016. № 14. С. 244-261.

3. Алексеева Ю. И. Речевое воплощение художественных деталей символического характера в романах В. Набокова // Известия Самарского научного центра РАН. 2010. № 3. Ч. 2. С. 455-457.

4. Арнольд И. В. Импликация как прием построения текста и предмет филологического изучения // Вопросы языкознания. 1982. № 4. С. 83-91.

5. Баранов А. Г. Функционально-прагматическая концепция текста. Ростов-на-Дону: Изд-во РГУ, 1993.182 с.

6. Барт Р. Лингвистика текста // Новое в зарубежной лингвистике: лингвистика текста. М.: Прогресс, 1978. Вып. VIII. С. 442-449.

7. Болотнова Н. С. Художественный текст в коммуникативном аспекте и комплексный анализ единиц лексического уровня. Томск: Изд-во Томского ун-та, 1992. 309 с.

8. Бондарко А. В. Эксплицитность / имплицитность в общей системе категоризации семантики // Семантико-дискурсивные исследования языка: Эксплицитность / имплицитность выражения смыслов: материалы международной научной конференции / под ред. С. С. Ваулиной. Калининград: Изд-во РГУ им. И. Канта, 2006. С. 22-33.

9. Винокур Т. Г. Говорящий и слушающий: варианты речевого поведения. М.: Наука, 2007. 176 с.

10. Гальперин И. Р. Текст как объект лингвистического исследования. Изд-е 4-е, стер. М.: КомКнига, 2006. 144 с.

11. Говорова В. Ф. Прагматическая функция научного текста // Актуальные проблемы прагмалингвистики в контексте межкультурной коммуникации: материалы Всерос. науч. конф. (7-8 дек. 2006 г.). Тольятти: ТГУ, 2006. С. 124-127.

12. Гусева Е. В. Художественная деталь как жанрообразующий признак // Известия Самарского научного центра РАН. 2012. № 2. Ч. 6. С. 1502-1508.

13. Дейк Т. А., ван. Вопросы прагматики текста // Текст: аспекты изучения семантики, прагматики и поэтики: сб. ст. М.: Эдиториал УРСС, 2001. С. 90-167.

14. Демьянков В. 3. Понимание как интерпретирующая деятельность // Вопросы языкознания. 1983. № 6. С. 58-67.

15. Добин Е. С. Сюжет и действительность. Искусство детали. М.: Советский писатель, 1981. 432 с.

16. Дымарский М. Я. Проблемы текстообразования и художественный текст (на материале русской прозы ХІХ-ХХ вв.). М.: Эдиториал УРСС, 2001. 328 с.

17. Есин А. Б. Принципы и приемы анализа литературного произведения. М.: Флинта, 2011. 248 с.

18. Жаворонок И. А. Художественная деталь и ее функции в творчестве Л. Е. Улицкой: дисс. ... к. филол. н. Тверь, 2012. 172 с.

19. Звегинцев В. А. Предложение и его отношение к языку и речи. М.: Изд-во МГУ, 1976. 307 с.

20. Кропоткин П. Русская литература. Идеал и действительность. М.: Русский издательский центр, 2003. 173 с.

21. Кузнецова А. В. Рецептивно-интерпретативное пространство художественного текста: проблемная парадигма // Филологические науки. Вопросы теории и практики. 2019. Т. 12. Вып. 12. С. 118-121.

22. Кузнецова А. В. Метатекст в художественном тексте: прагматика и функции // Филологические науки. Вопросы теории и практики. 2020. Т. 13. Вып. 9. С. 265-269.

23. Кухаренко В. А. Интерпретация текста. М.: Просвещение, 1988. 192 с.

24. Лингвистический энциклопедический словарь / гл. ред. В. Н. Ярцева. Изд-е 2-е, доп. М.: Большая Рос. энцикл., 2002. 709 с.

25. Лихачев Д. С. Внутренний мир художественного произведения // Поэтика. Труды русских и советских поэтических школ / сост. Дьюла Кирай, Арпад Ковач. Tankonykiado - Budapest, 1982. С. 725-736.

26. Лотман Ю. М. Структура художественного текста. М.: Искусство, 1970. 384 с.

27. Лукин В. А. Художественный текст. Основы лингвистической теории и элементы анализа. М.: Ось-89, 1999. $192 \mathrm{c}$.

28. Лукьянчук Н. В. Теоретические предпосылки исследования художественной детали // Язык и культура (Новосибирск). 2012. № 3. С. 62-66.

29. Манн Ю. В. Сквозь призму художественной детали: дополнение к теме // Гуманитарное пространство. 2013. № 4. С. 702-710.

30. Матвеева Г. Г. Актуализация прагматического аспекта научного текста. Ростов н/Д: Рост. гос. ун-т, 1984.132 с.

31. Милосердова Е. В. Имплицитность как лингвопрагматическая категория и ее роль в разных типах дискурса // Вестник Тамбовского университета. Серия «Гуманитарные науки». 2011. Вып. 12 (104). С. 727-732. 
32. Никитин М. В. Курс лингвистической семантики. СПб: Научный центр проблем диалога, 1996. 760 с.

33. Николаева Т. М. Единицы языка и теория текста // Исследования по структуре текста. М.: Наука, 1987. С. 27-57.

34. Падучева Е. В. Семантические исследования (семантика времени и вида в русском языке; семантика нарратива). Изд-е 2-е, испр. и доп. М.: Языки русской культуры, 2010. 480 с.

35. Просянникова О. И. Актуализация имплицитности художественной детали в текстах психологической прозы: на материале английского психологического рассказа XX века: дисс. ... к. филол. н. СПб., 2004. 174 с.

36. Садофьева А. Ю. Культурно-бытовая деталь в художественном тексте // Вестник Московского университета. Серия 19. Лингвистика и межкультурная коммуникация. 2008. № 2. С. 129-136.

37. Степанов Ю. С. В поисках прагматики (проблема субъекта) // Известия Академии наук СССР. Серия литературы и языка. 1981. Т. 40. № 4. С. 325-332.

38. Телия В. Н. Вторичная номинация и ее виды // Языковая номинация (виды наименования). М.: Наука, 1977. C. 89-132.

39. Ткачёва Р. А., Михайлова Н. Д., Витлинская Л. Г. Образотворческая роль художественной детали в рассказе А. П. Чехова «Враги» // Международный научно-исследовательский журнал. 2020. № 12 (102). Ч. 3. С. 176-180.

40. Чернец Л. В. О художественной детали // Русский язык и литература для школьников. 2010. № 8. С. 10-15.

41. Чехов А. П. Дама с собачкой [Электронный ресурс] // Чехов А. П. Полное собрание сочинений и писем: в 30-ти т. URL: http://az.lib.ru/c/chehow_a_p/text_0100.shtml\#10 (дата обращения: 02.09.2021).

42. Шмидт Е. Д. Эволюция художественной детали в тексте словесного портрета: на материале английской художественной прозы XVIII-XX вв.: дисс. ... к. филол. н. СПб., 2006. 175 с.

\section{Информация об авторах | Author information}

RU Tрубкина Анна Ивановна ${ }^{1}$, к. филол. н.

${ }^{1}$ Южный федеральный университет, г. Ростов-на-Дону

EN Trubkina Anna Ivanovna ${ }^{1}, \mathrm{PhD}$

${ }^{1}$ Southern Federal University, Rostov-on-Don

${ }^{1}$ aitrubkina@sfedu.ru

\section{Информация о статье | About this article}

Дата поступления рукописи (received): 31.07.2021; опубликовано (published): 30.09.2021.

Ключевые слова (keywords): художественная деталь; прагматика; имплицированные смыслы; смысловое пространство текста; художественный текст; literary detail; pragmatics; implicit meanings; semantic space of the text; literary text. 